Jurnal ELTIKOM, Vol. 1 No.1, Juni 2017, Hal 39-46

ISSN 2598-3245 (Print), ISSN 2598-3288 (Online)

Tersedia Online di http://eltikom.poliban.ac.id

\title{
SISTEM INFORMASI PEMERIKSAAN PASIEN KLINIK
}

\author{
Abdul Rozaq ${ }^{1)}$, Novi Shintia ${ }^{2)}$, Yulia Harmini ${ }^{3)}$, Nadia Saraswati ${ }^{4}$ \\ ${ }_{1,2,3)}$ Politeknik Negeri Banjarmasin \\ e-mail: rozaq@poliban.ac.id ${ }^{1)}$,novi_shintia@yahoo.co.id ${ }^{2)}$,yharmini@gmail.com ${ }^{3)}$, \\ nadia.smada@gmail.com ${ }^{4}$
}

\begin{abstract}
The problem that happened at clinic drg.Lili Setiyowati is a Services performed so far are still done manually well in patient registration and data archiving. This system is considered ineffective and efficient. Given the growing number of patient so that service are donw more slowly and take a long time. The purpose of this research is to design, build, and implement patient information examination system in clinic drg.Lili Setiyowati. Method of developing system used is SDLC (System Development Life Cycle) method which consists of system planning, system analysis, system design, system implementation, and system maintenance. For data collection method used is observation and interview for system design is divided into two that is logical system like DFD, CDM, and PDM, and the second system is a physical system. The conclusion of this research is the information system made able to answer the problem faced by the parties concerned, thus making the service to the patient more comfortable, easy, and fast.
\end{abstract}

Keywords : Information System, Examination, Patient, and Clinic drg. Lili Setiyowati.

ABSTRAK

Permasalahan yang terjadi pada Klinik drg. Lili Setiyowati adalah pelayanan yang dilakukan selama ini masih dilakukan secara manual baik dalam pendaftaran pasien, registrasi pasien dan pengarsipan data pasien. Sistem ini sudah dianggap tidak efektif dan efisien lagi. Mengingat jumlah pasien yang mulai bertambah sehingga pelayanan yang dilakukan menjadi lambat dan memakan wartu yang lama. Tujuan dari penelitian ini adalah untuk merancang, membangun dan mengimplementasikan Sistem Informasi Pemeriksaan Pasien Klinik drg. Lili Setiyowati. Metode pengembangan sistem yang digunakan adalah metode SDLC (System Development Life Cycle) yang terdiri dari Perencanaan Sistem, Analisis Sistem, Perancangan Sistem, Penerapan Sistem dan Pemeliharaan Sistem. Untuk metode pengumpulan data yang digunakan adalah observasi dan wawancara untuk desain sistem terbagi menjadi dua yaitu sistem logis seperti perancangan DFD, CDM dan PDM, dan sistem kedua yaitu sistem fisik. Kesimpulan dari penelitian ini adalah sistem informasi yang dibuat mampu menjawab permasalahan yang dihadapi oleh pihak yang bersangkutan, sehingga membuat pelayanan ke pasien menjadi lebih nyaman, mudah dan cepat.

Kata Kunci : Sistem Informasi, Pemeriksaan, Pasien, Klinik drg. Lili Setiyowati.

\section{PENDAHULUAN}

Pada saat ini perkembangan teknologi dan informasi sangat pesat dan semakin dikenal luas oleh masyarakat umum, mulai dari media informasi yang awalnya hanya digunakan pada media kertas, sekarang berpindah ke media komputerisasi. Hampir di semua perusahaan, organisasi, lembaga, rumah sakit dan instansi pemerintahan memerlukan pengelolaan data dan informasi yang cepat, tepat dan akurat dalam meningkatkan kinerjanya, salah satunya klinik yang di dalamnya juga terdapat pengelolaan informasi. Dalam pelayanan informasi kebanyakan klinik belum menggunakan komputer. Klinik gigi sebagai salah satu tempat pelayanan umum yang membutuhkan suatu sistem informasi yang cepat, tepat, dan cukup untuk meningkatkan pelayanannya kepada para pasien dan pihak yang terkait di dalamnya. Dengan lingkup pelayanan yang begitu luas, tentunya banyak sekali permasalahan yang terjadi dalam proses pelayanan di klinik gigi.

Klinik gigi merupakan sebuah klinik yang bergerak didalam bidang jasa kesehatan gigi, artinya semua kegiatan itu dilakukan tanpa bantuan komputer, sehingga dapat mengakibatkan catatan dan berbagai data klinik hilang atau rusak, karena hanya dicatat di kertas dan membutuhkan tempat atau ruang khusus untuk menyimpan catatan-catatan tersebut. 
Saat ini sistem pengelolaan informasi pada klinik drg. Lili Setiyowati masih dilakukan secara manual, membutuhkan waktu yang cukup lama dan belum baik dari segi pelayanannya seperti pencatatan hasil dari pemeriksaan pasien dan terkadang ada beberapa data rekam medik pasien yang belum tercatat. Selain pengelolaan data-data klinik, pencarian data juga masih dilakukan secara manual. Pencarian data dan rekam medik pasien yang pernah berobat sebelumnya membutuhkan waktu yang lama karena jumlah data pasien yang terdaftar dan penumpukan data rekam mediknya cukup banyak. Oleh karenanya diperlukan suatu sistem informasi yang dapat menyediakan informasi dengan cepat, tepat, dan akurat sehingga mempermudah untuk mendapatkan informasi tentang pasien dari segi pelayanan untuk pendaftaran, pencarian data pasien, pencatatan hasil pemeriksaan pasien sampai proses penyelesaian administrasi yang baik di klinik drg. Lili Setiyowati sehingga lebih profesional dan lebih bisa mengatur manajemennya.

Berdasarkan uraian diatas maka perlu dilakukan penelitian untuk menghasilkan suatu sistem agar mempermudah pelayanan di Klinik drg. Lili Setiyowati dengan memanfaatkan teknologi komputerisasi yang berjudul Sistem Informasi Pemeriksaan Pasien Pada Klinik drg. Lili Setiyowati.

Dari uraian diatas tersebut dapat dirumuskan permasalahannya sebagai berikut :

1. Bagaimana menemukan permasalahan di Klinik drg. Lili Setiyowati sehingga perlu dikembangkanya Sistem Informasi Pemeriksaan Pasien Klinik drg. Lili Setiyowati?

2. Bagaimana merancang Sistem Informasi Pemeriksaan Pasien Klinik drg. Lili Setiyowati yang mampu memberikan pelayanan yang baik?

3. Bagaimana membangun Sistem Informasi Pemeriksaan Pasien Klinik drg. Lili Setiyowati menggunakan Delphi 2010 dan Database Mysql ?

4. Bagaimana mengimplementasikan Sistem Informasi Pemeriksaan Pasien Klinik drg. Lili Setiyowati menggunakan Delphi 2010 ?

Tujuan yang ingin dicapai dalam penelitian ini adalah sebagai berikut :

1. Untuk menemukan permasalahan di Klinik drg. Lili Setiyowati sehingga perlu dikembangkannya Sistem Informasi Pemeriksaan Pasien Klinik drg. Lili Setiyowati.

2. Untuk merancang Sistem Informasi Pemeriksaan Pasien Klinik drg. Lili Setiyowati yang mampu memberikan pelayanan yang baik.

3. Untuk membangun Sistem Informasi Pemeriksaan Pasien Klinik drg. Lili Setiyowati menggunakan Delphi 2010 dan Database Mysql.

4. Untuk mengimplementasikan Sistem Informasi Pemeriksaan Pasien Klinik drg. Lili Setiyowati menggunakan Delphi 2010.

Hasil penelitian ini diharapkan dapat memberikan kegunaan, yaitu :

1. Aplikasi ini diharapkan mampu membantu memecahkan masalah dengan tepat dan kepada para medik khususnya dokter yang melakukan praktek di rumah agar beralih dari sistem manual menjadi sistem komputerisasi dalam pengelolaan data pasien dan pencatatan hasil pemeriksaan kondisi kesehatan pasien.

2. Memberikan konstribusi agar mempermudah dalam pelayanan pengelolaan data pasien pada klinik drg. Lili Setitowati.

\section{METODE PENELITIAN}

A. Jenis Penelitian

Jenis penelitian yang digunakan dalam pembuatan laporan ini adalah Penelitian Terapan (Applied Research). Penelitian Terapan adalah salah satu jenis penelitian yang bertujuan untuk memberikan solusi atas permasalahan tertentu secara praktis. Hasil penelitian tidak perlu sebagai suatu penemuan baru, tetapi merupakan aplikasi baru dari penelitian yang telah ada. Ciri utama dari penelitian ini adalah manfaat atau dampaknya dapat dirasakan secara langsung.

B. Lokasi Penelitian

Penelitian dilakukan di Klinik drg. Lili Setiyowati yang beralamat di Jalan Ahmad Yani KM 7,2 Jalan Mahligai Komplek Mahligai Land kav 2 Banjarmasin, Kalimantan Selatan.

C. Sumber Data

1. Sumber Data Primer 
Data primer adalah data yang diperoleh secara langsung dari objek penelitian. Penulis melakukan pengamatan langsung tentang keluhan dan saran dari pihak yang bersangkutan untuk merancang sistem informasi di klinik drg. Lili Setiyowati.

2. Sumber Data Skunder

Data skunder adalah data yang diperoleh penelitian secara tidak langsung melalui media perantara (diperoleh dan dicatat oleh pihak lain) yaitu berupa bukti, catatan yang telah tersusun dalam arsip atau data dokumentasi yang diperlukan untuk penulis dalam penelitian.

\section{Teknik Pengumpulan Data}

1. Observasi

Observasi adalah pengumpulan data yang dilakukan dengan cara pengamatan secara langsung atau terjun ke lapangan rangka memperoleh data yang cepat dan akurat. Dalam penelitian ini tempat yang akan diteliti adalah Klinik drg. Lili Setiyowati khususnya dalam masalah pembuatan data, pendaftaran pasien, dan pencatatan rekam medik. Observasi merupakan salah satu teknik pengumpulan data atau fakta-fakta yang cukup efektif dan akurat untuk mempelajari suatu sistem.

Hasil observasi yang dilakukan penulis dalam pengamatan ini di antaranya adalah :

a. Melihat cara pendaftaran pasien yang ingin berobat setiap harinya

b. Melihat cara pendaftaran pasien baru

c. Melihat cara pencatatan rekam medik pasien

d. Melihat cara pembayaran administrasi pasien

2. Wawancara

Wawancara merupakan suatu cara atau metode untuk mengumpulkan berita, data atau fakta di lapangan dengan mengajukan pertanyaan langsung ke pemilik Klinik drg. Lili Setiyowati tersebut dengan bertatap muka langsung dengan narasumbernya.

Hal-hal yang diwawancari penulis diantaranya adalah:

a. Menanyakan tentang sistem yang diterapkan dalam mengelola data-data pasien apakah menggunakan sistem komputerisasi atau menggunakan buku agenda sebagai penyimpanan datanya.

b. Menanyakan tentang cara pendaftaran pasien baru dan syarat-syarat yang diperlukan dalam pendaftarannya.

c. Menanyakan bagaimana cara pendaftaran pasien jika ingin berobat apakah menggunakan nomor antrian atau mendaftar sehari sebelum berobat.

d. Menanyakan bagaimana cara pembayaran administrasi pasien.

E. Metode Pengembangan Sistem

SDLC (System Development Life Cycle) atau Siklus Hidup Pengembangan Sistem adalah proses pembuatan dan pengubahan sistem serta model dan metodologi yang digunakan untuk mengembangkan sistem-sistem tersebut. Dengan mengikuti metode atau prosedur-prosedur yang diberikan oleh suatu metodologi, maka pengembangan sistem diharapkan dapat memberikan hasil yang sesuai dengan tujuan pembuatan sistem. Konsep ini umumnya merujuk pada sistem komputer atau informasi

\section{HASIL DAN PEMBAHASAN}

A. Analisis Kebutuhan Sistem

Kebutuhan fungsional adalah jenis kebutuhan yang berisikan proses-proses apa saja yang dilakukan oleh sistem informasi dan apa yang dihasilkan sistem. Adapun kebutuhan fungsional dalam penelitian ini sebagai berikut :

1. Sistem harus dapat melakukan pendataan pasien

a) Pengguna bisa menambahkan atau menginput data pasien baru (pasien yang baru pertama kali pemeriksaan di Klinik).

b) Pengguna bisa melihat data pasien secara keseluruhan.

c) Pengguna bisa melakukan perubahan terhadap data pasien.

d) Pengguna bisa menampilkan data pasien.

e) Pengguna bisa mencetak kartu rekam medik pasien.

f) Pengguna bisa melakukan pencarian data pasien.

2. Sistem harus dapat melakukan pendataan admin 

a) Pengguna dapat menambahkan atau menginput data admin.
b) Pengguna bisa melihat data admin.
c) Pengguna bisa mengubah atau memperbaharui data admin.
d) Pengguna bisa menampilkan data admin secara keseluruhan.
e) Pengguna bisa menghapus data admin.
f) Pengguna bisa melakukan pencarian data admin.

3. Sistem harus dapat melakukan pendataan diagnosa untuk rekam medik
a) Pengguna bisa menambahkan atau menginput data diagnosa untuk rekam medik.
b) Pengguna bisa menampilkan data diagnosa rekam medik.
c) Pengguna bisa mengubah atau memperbaharui data rekam medik.
d) Pengguna bisa melaukan pencarian data diagnosa untuk rekam medik.
e) Pengguna bisa menyimpan data diagnosa untuk rekam medik.

4. Sistem harus bisa melaporkan jumlah pasien yang berobat dalam periode tertentu.

Kebutuhan Non Fungsional :

1. Operasional
a) Perangkat Keras (Hardware)

1. Processor Pentium 4 atau lebih

2. RAM $2 \mathrm{~Gb}$ atau lebih

3. Perangkat pendukung lainnya

4. Hardisk $320 \mathrm{~Gb}$ untuk media penyimpanan

5. Printer untuk mencetak kartu rekam medik dan laporan

b) Perangkat Lunak (Software)

Perangkat lunak diperlukan untuk pembuatan dan pemprosesan data dari sistem yang akan diusulkan sehingga kinerja program berjalan dengan baik. Yang diperlukan untuk perangkat lunak sebagai berikut :

1. Menggunakan sistem operasi Windows 7 atau lebih.

2. Embarcadero Delphi 2010 Development Programming.

3. MySQL server 5.0 atau lebih.

2. Keamanan (security)

Sistem yang dilengkapi dengan username dan password yang hanya bisa dibuka oleh pengguna yang memiliki hak akses.

3. Informasi

Sistem yang dapat melakukan pencarian data, dan menampilkan data yang diperlukan.

4. Kinerja

Waktu yang digunakan dalam penginputan data tidak lebih dari 3 menit. Fasilitas membuat kartu rekam medik lebih efisien, dan untuk mencari data yang diperlukan dilengkapi dengan search.

B. Pemecahan Masalah

Pembuatan sistem baru sebagai pengembang sistem lama yaitu melalui tahapan

- Pembuatan DFD

- Normalisasi

- Conceptual Data Model

- Struktur database

- Rancangan antar muka

C. Pembuatan DFD

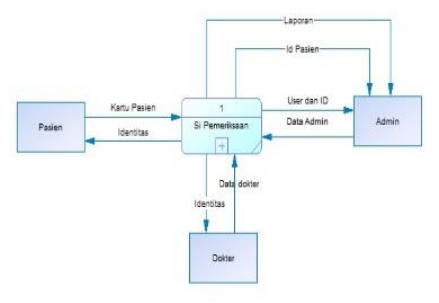


Data Flow Diagram (DFD) adalah suatu model yang dibuat untuk menggambarkan arus dari data sistem, yang penggunaannya sangat membantu untuk memahami sistem secara logika, terstruktur dan jelas.

D. Normalisasi

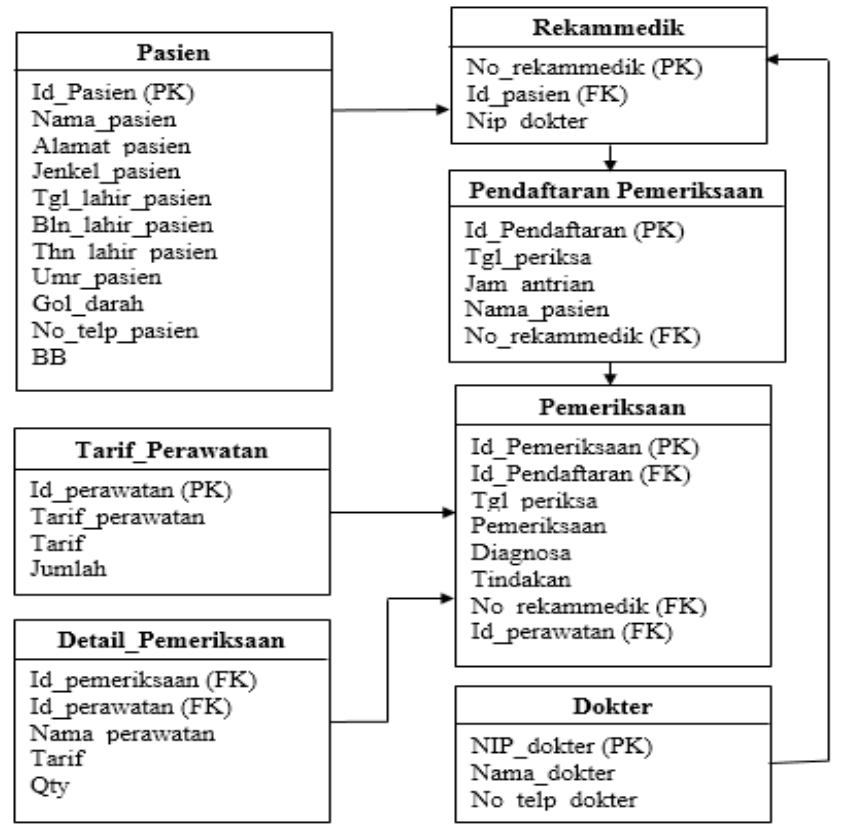

Gambar 2. Normalisasi

Normalisasi merupakan salah satu cara pendekatan atau teknik yang digunakan dalam membangun desain logik basis data dan relasi dengan menerapkan sejumlah aturan dan kriteria.

E. Conceptual Data Model

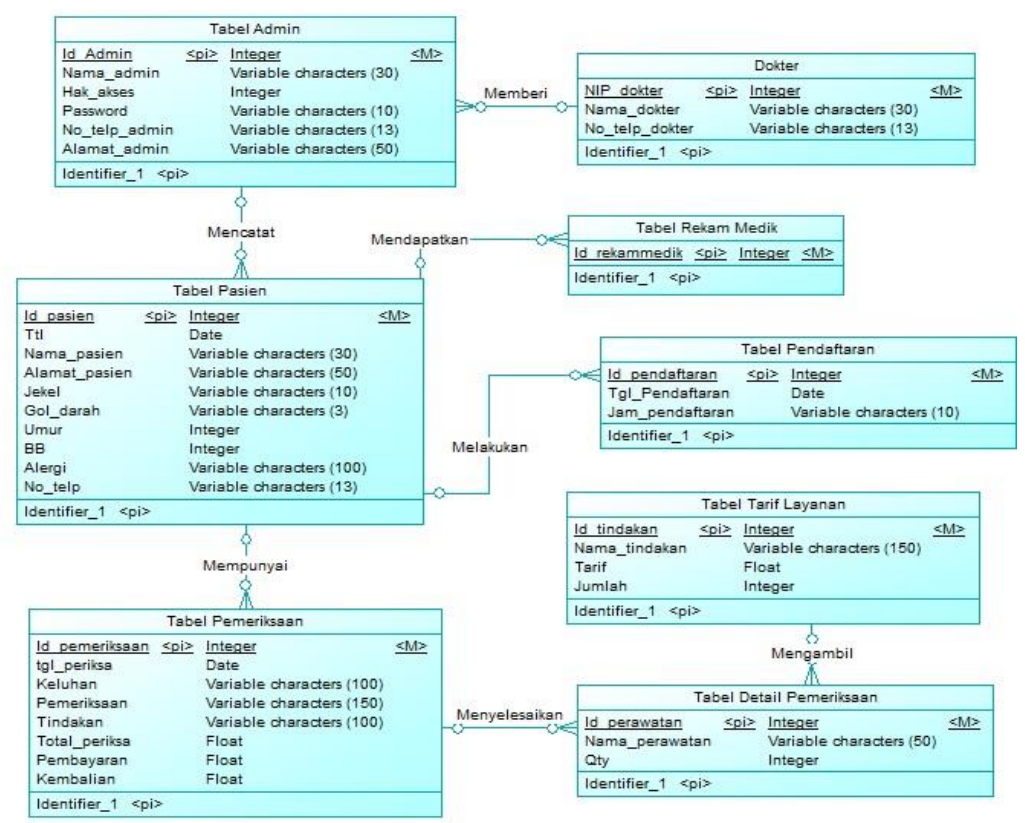

Gambar 3. Conceptual Data Model

Conceptual Data Model menggambarkan struktur logika seccara keseluruhan mulai dari sebuah database. CDM berisi data dari objek yang belum diimplementasikan ke physical database, CDM memberikan sebuah gambaran untuk dijalankan oleh pengguna. 
F. Struktur Database

Tahap berikutnya adalah membuat struktur database, dalam perancangan sistem dibuat struktur database yang dijadikan acuan dalam membuat program aplikasinya.

\section{G. Implementasi}

Desain Antar Muka (Input) adalah salah satu rancangan masukan yang mengatur tata letak dari suatu program, dengan tujuan untuk mengetahui seperti apa antar muka dari suatu sistem ketika perangkat lunak dikembangkan. Rancangan antar muka menggambarkan proses menambahkan data, mengedit data, menghapus data dan lain-lain.

Implementasi merupakan tahapan penggunaan sistem yang telah dirancang dengan menggunakan teknologi yang sudah dipilih. Untuk mengimplementasikan program Sistem Informasi Pemeriksaan Pasien Klinik drg. Lili Setiyowati maka harus dilakukan beberapa langkah, yaitu :

1. Aplikasi sistem informasi yang sudah dibuat exe

2. Aplikasi MySQL 5.0 kemudian import database sipemeriksaan

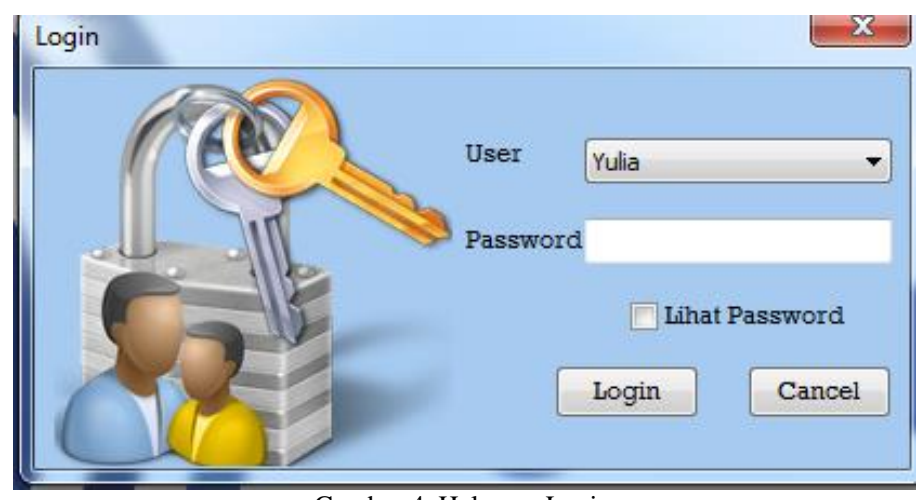

Gambar 4. Halaman Login
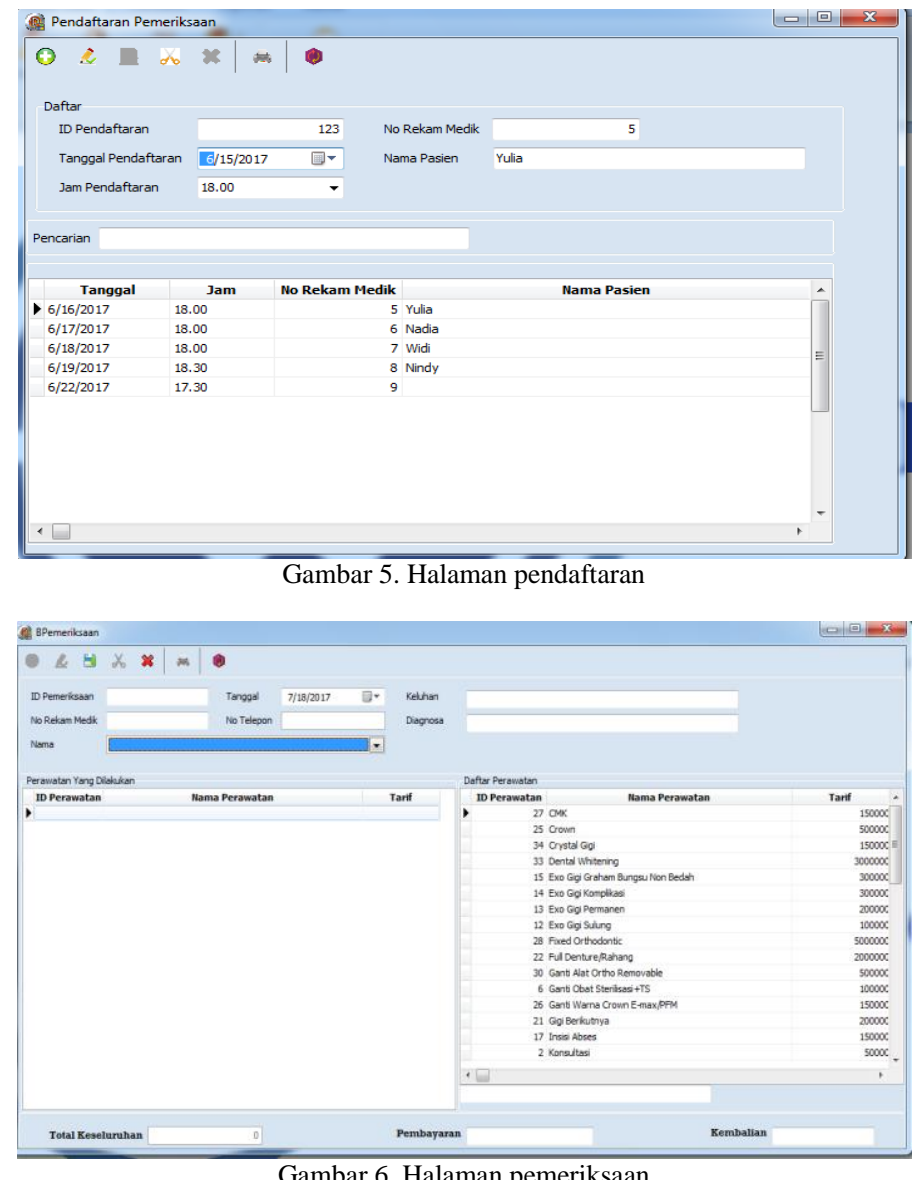


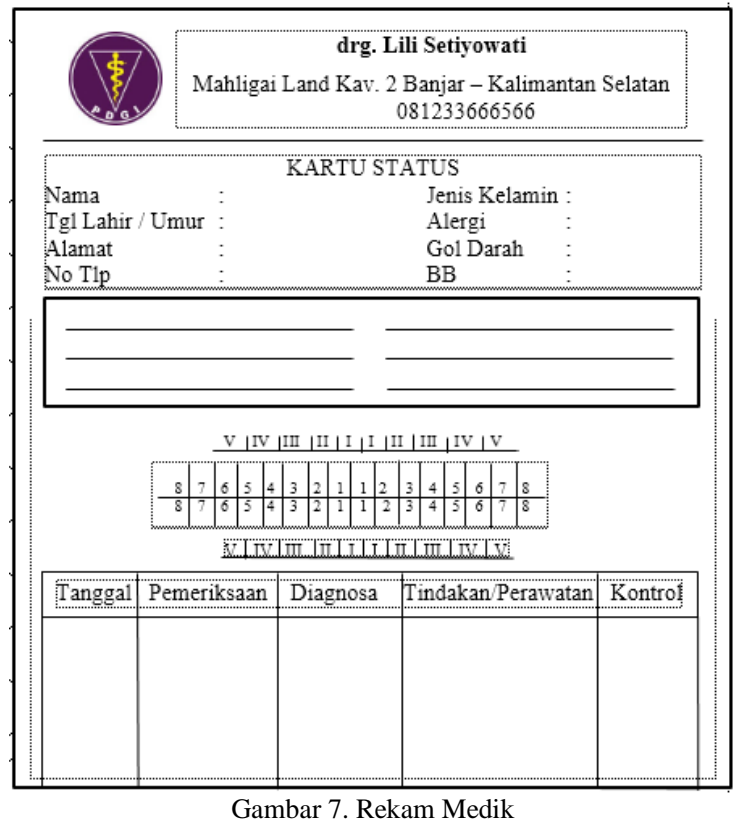

H. Pengujian

Setelah dilakukan uji coba oleh admin maka di peroleh singkat perbandingan sebagai berikut:

\begin{tabular}{|c|l|l|l|}
\hline No & \multicolumn{1}{|c|}{ Kategori } & \multicolumn{1}{|c|}{ Sistem Lama } & \multicolumn{1}{|c|}{ Sistem Baru } \\
\hline 1 & Integritas & $\begin{array}{l}\text { Tidak ada, file } \\
\text { terpisah-pisah }\end{array}$ & Ada sangat menunjang \\
\hline 2 & $\begin{array}{l}\text { Otomatisasi dan } \\
\text { Validasi }\end{array}$ & Tidak ada & $\begin{array}{l}\text { Ada, karena program di } \\
\text { rancang menggunakan } \\
\text { pesan peringatan jika ada } \\
\text { data yang dimasulkan tidak } \\
\text { sesuai, serta penggunaan } \\
\text { password agar tidak semua } \\
\text { orang bisa mengakses } \\
\text { program tersebut }\end{array}$ \\
\hline 3 & Teknikal Error & Tidak ada & $\begin{array}{l}\text { Jarang terjadi, Karena data } \\
\text { sudah memiliki primary key } \\
\text { yang bersifat unik agar data } \\
\text { tidak sama dengan yang lain }\end{array}$ \\
\hline 4 & Human Error & Tidak ada & Bisa diminimalkan \\
\hline 5 & Redudansi & Tidak ada & Tidak terjadi lagi \\
\hline 6 & Back Up & Dapat ditingkatkan \\
\hline 7 & $\begin{array}{l}\text { Kecepatan } \\
\text { Pengolahan } \\
\text { Data }\end{array}$ & Tidak ada & $\begin{array}{l}\text { Lebih cepat karena ini } \\
\text { sistem yang dirancang untuk } \\
\text { memudahkan pekerjaan }\end{array}$ \\
\hline
\end{tabular}

Gambar 6. Perbandingan Uji Coba Program

\section{KESIMPULAN}

Adapun kesimpulan yang dapat diambil dari penelitian yang telah dilakukan penulis sebagai berikut:

1. Klinik gigi sebagai salah satu tempat pelayanan umum yang membutuhkan suatu sistem informasi yang cepat, tepat, dan cukup untuk meningkatkan pelayanannya kepada para pasien dan pihak yang terkait di dalamnya. Dengan lingkup pelayanan yang begitu luas, tentunya banyak sekali permasalahan yang terjadi dalam proses pelayanan di klinik gigi.

2. Delphi adalah sebuah bahasa pemprograman, development, aplikasi windows, aplikasi grafis, aplikasi visual, bahkan aplikasi jaringan dan berbasis internet. Delphi memiliki lingkungan pemprograman terpadu IDE(Intergrated Development Environment), dengan IDE semua yang diperlukan dalam pengembangan dalam kondisi normal semua telah tersedia

3. Dari beberapa permasalahan yang penulis temukan dari tiap-tiap analisis, maka penulis melakukan solusi berupa perancangan umum dengan cara flowchart sistem, dan Data Flow Diagram, sedangkan untuk perancangan database, penulis membuat Conceptual Data Model dan Physical Data Model.

4. Setelah diterapkannya Sistem Informasi Pemeriksaan Pasien Klinik drg. Lili Setiyowati maka perubahan yang dihasilkan antara lain, dari kinerja mampu melakukan pencarian data pasien dengan cepat dan otomatis. Dari segi ekonominya mampu meningkatkan waktu pengerjaan dan mampu 
meyediakan laporan-laporan serta informasi secara tepat sesuai keinginan, serta pengendalian dan pelayanan yang mampu menyimpan data untuk waktu dan jumlah yang besar, dan dapat meningkatkan kualitas pelayanan pada klinik tersebut.

\section{SARAN}

1. Klinik yang terkait harus mampu menyediakan fasilitas berupa seperangkat komputer yang memliki spesifikasi seperti yang sudah disebutkan.

2. User atau pengguna harus diberi pelatihan mengenai cara untuk mengoprasikan program.

3. Sistem pengolahaan data ini diperiksa secara berkala agar permasalahan yang muncul dapat diantisipasi dengan optimal.

4. Sistem ini bisa terus dikembangkan agar menjadi sistem yang lebih menunjang perkembangan teknologi dan kebutuhan akan sistem informasi yang lebih kompeten dimasa yang akan datang.

5. Keamanan data sebaiknya dikelola dengan benar dan berkesinambungan, serta perawatan hardware maupun back up data adalah sesuatu yang mutlak untuk dilakukan.

\section{DAFTAR PUSTAKA}

[1] Hutahaean, Jeperson. 2015. Konsep Sistem Informasi. Yogyakarta: Deepublish.

[2] Kadir, Abdul. 2008. Konsep dan Tuntunan Praktis Basis Data. Yogyakarta: ANDI Yogyakarta.

[3] - 2001. Pemograman Database Menggunakan Delphi 1. Vol. 1. Yogyakarta: Salemba Empat.

[4] —. 2008. Pengenalan Sistem Informasi. Yogyakarta: ANDI.

[5] Marlinda. 2004. Sistem Basis Data. Yogyakarta: Andi Offset.

[6] Muhammad Junaidi, Tuti Alawiyah. 2013. Laporan Tugas Akhir Sistem Informasi Pelayanan Kesehatan Pada Praktik Dokter Di Apotek Perintis. Banjarmasin: Politeknik Negeri Banjarmasin.

[7] Munir, dan Wawan Setiawan. 2006. Pengantar Teknologi Informasi. Bandung: Universitas Pendidikan Indonesia.

[8] Novienty, Lolita Dewi, dan Aditya Prapanca. 2016. "Sistem Informasi Manajemen Sekolah Berbasis Web." Manajemen Informatika 3.

[9] Romzi, M. 2014. "Rancang Bangun Sistem Informasi Inventaris Laboratorium AMIK AKMI Baturaja." Media Informasi dan Komputer 10.

[10] Sutarman. 2013. "Daud F. Tatang." Sistem Informasi Manajemen Sekolah Berbasis Web 85.

[11] Trimarsih, Yunita. 2014. "Sistem Informasi Berbasis Web Pada Privat Awal Belajar Cerdas Pada Web dan MySQL." Media Informasi dan Komputer 44.

[12] Wahyudi, Bagus. 2012. Delphi 2010 dan Firebird Membuat Aplikasi Mini Market Client Server (Support Barcode Scanner). Yogyakarta: Gava Media. 